\title{
Inovação no setor de biodiesel dos principais países produtores: 0 papel da demanda induzida entre 2000 e $2011^{1}$
}

\author{
The biodiesel sector innovation in the main producing countries: the \\ role of induced demand from 2000-2011
}

Lora dos Anjos Rodrigues ${ }^{1}$ (1), José Gustavo Féres² (1)

${ }^{1}$ Instituto de Ciências Sociais Aplicadas, Universidade Federal de Alfenas (UNIFAL), Varginha (MG), Brasil. E-mail: lora.rodrigues@unifal-mg.edu.br

2Instituto de Pesquisa Econômica Aplicada (IPEA), Rio de Janeiro (RI), Brasil. E-mail: jose.feres@ipea.gov.br

\begin{abstract}
Como citar: Rodrigues, L. A., \& Féres, J. G. (2022). Inovação no setor de biodiesel dos principais países produtores: 0 papel da demanda induzida entre 2000 e 2011. Revista de Economia e Sociologia Rural, 60(3), e234493. https://doi. org/10.1590/1806-9479.2021.234493
\end{abstract}

Resumo: Tem-se por objetivo investigar se a tendência de alta no preço do petróleo e as políticas públicas regulatória e fiscal afetam a inovação no setor de biodiesel. Também, se há influência da proporção do gasto do governo em Pesquisa e Desenvolvimento (P\&D). A existência de uma relação entre o preço relativo do petróleo e a inovação no biodiesel é fundamentada na teoria da inovação induzida, proposta por Hicks (1932) e formalizada por Ahmad (1966). Para mensurar a inovação, empregam-se dados de patentes em biodiesel depositadas (por residentes) no Brasil, Estados Unidos, Alemanha, França, Espanha, Reino Unido, Áustria e República Checa de 2000 a 2011. Aplica-se o estimador de Método dos Momentos Generalizados (GMMR) no modelo de Poisson em painel de Efeito Fixo. Os resultados indicam que o preço do petróleo e a existência de política regulatória e fiscal são fatores demand-pull, que estimulam a inovação no biodiesel por aumentar sua demanda e a expectativa de retorno. Já o investimento governamental em P\&D constitui um fator technology-push, que afeta a inovação pelo lado da oferta, na medida que aumenta a capacidade tecnológica da qual o setor de biodiesel pode se beneficiar.

Palavras-chave: biodiesel, inovação, preço do petróleo, políticas públicas.

\begin{abstract}
The objective of this article is to investigate whether market factors, especially the upward trend in oil price, and whether regulatory and fiscal public policies positively affect innovation in the biodiesel sector Also, we intend to investigate whether the proportion of government spending on Research and Development (R\&D) has a positive influence on biodiesel innovation. The relation between the relative oil price and innovation in biodiesel is based on the induced innovation theory proposed by Hicks (1932) and formalized by Ahmad (1966). Deposited patents by the resident were used to measure innovation in Brazil, United States, Germany, France, Spain, United Kingdom, Austria, and the Czech Republic between 2000 and 2011. They are the main producer countries. The Generalized Moments Method (GMM) estimator is applied to the Poisson model in a Fixed Effect panel. It is proper for count data and for taking into account the endogeneity. The results indicate that the oil price and public policies are demand-pull factors that stimulate innovation in biodiesel by increasing its demand and expected return. On the supply side, government investment in R\&D is a technology-push factor because it increases the technological capacity that benefits the biodiesel sector.
\end{abstract}

Keywords: biodiesel, innovation, oil price, public policies.

\section{Introdução}

O diesel é o principal derivado do petróleo consumido no setor de transportes, representando, por exemplo, 48,1\% da energia consumida pelo setor no Brasil em 2012 (Empresa de

\footnotetext{
Este artigo é resultante da tese desenvolvida no Programa de Pós-Graduação em Economia Aplicada da Universidade Federal de Viçosa (UFV) com apoio de bolsa do Conselho Nacional de Desenvolvimento Científico e Tecnológico (CNPq).

2 Sigla em inglês: GMM - Generalized Moments Method.
} 
Pesquisa Energética, 2013b) e cerca de 20 vezes o consumo da gasolina na União Europeia em 2010 (European Union, 2012). Os transportes foram responsáveis por 62,3\% do consumo mundial de petróleo (International Energy Agency, 2013), constituindo-se no segundo maior setor emissor de gases de efeito estufa $(\mathrm{GEE})^{3}$ ao contabilizar $22 \%$ do total de emissões de gás carbônico $\left(\mathrm{CO}_{2}\right)$ proveniente da queima de combustíveis fósseis em 2010 (International Energy Agency, 2012). Na medida em que o biodiesel é consumido predominantemente neste setor, constitui-se um substituto efetivo para a redução de GEE. Sua importância como potencial redutor torna-se mais evidente quando se considera que os veículos movidos a diesel emitem a maior quantidade de $\mathrm{CO}_{2}$ por litro dentre os veículos motorizados (Carvalho, 2011).

Segundo o Greenpeace (2016), a transição energética em direção a uma economia de baixo carbono já começou e cabe aos agentes econômicos escolherem em qual lado da história querem estar. Em seu relatório, a partir de projeções de cenários futuros, aponta que os biocombustíveis serão fundamentais nos casos em que o uso da eletricidade não é o mais indicado no setor de transporte.

O biodiesel tem sua produção e consumo crescentes e se configura como o segundo principal biocombustível no mundo, representando 21,3\% do total produzido em 2011 (High Level Panel of Experts on Food Security and Nutrition, 2013) e 31\% do total ofertado em 2012 (British Petroleum, 2013). Esse crescimento pode ser entendido, em parte, como uma resposta às crescentes preocupações com os impactos negativos das mudanças climáticas e da degradação ambiental sobre a atividade econômica, saúde humana, entre outros.

Visto que o uso de combustíveis fósseis é apontado como um dos responsáveis por tais problemas, as nações têm estimulado a produção e o consumo de biocombustíveis, como fonte alternativa, por meio de leis e programas específicos que, muitas vezes, asseguram subsídios e/ ou abatimentos fiscais, dentre outros mecanismos de suporte. As ações dos governos nacionais também têm sido motivadas por tradicionais preocupações com a segurança energética ${ }^{4}$ relacionada à tendência de alta no preço do petróleo, visando reduzir a dependência de energia não renovável.

Em 2003, a União Europeia estabeleceu metas voluntárias para o uso de biocombustíveis nos transportes através da Directive to promote the Use of Biofuels or other Renewable Fuels for Transport (2003 Biofuels Directive). Somente em 2009, as metas tornaram-se obrigatórias para os biocombustíveis e outras energias renováveis pela aprovação da Directive on the Promotion of the Use of Energy from Renewable Sources (2009 Renewable Energy Directive - RED). A RED estabeleceu que $20 \%$ do total de energia consumida nos 27 países deveria ter origem em fontes renováveis até 2020. Para o transporte rodoviário, a energia renovável, predominantemente os biocombustíveis, deveria representar $10 \%$ da energia consumida no setor ${ }^{5}$. Nos Estados Unidos, em 2007, o Energy Independence and Security Act (EISA) definiu o novo Renewable Fuels Standard (RFS II), estabelecendo que a produção anual de biocombustíveis teria que alcançar 36 bilhões de galões até 2022, dos quais 21 bilhões deveriam ser de biocombustíveis avançados ${ }^{6}$. No Brasil, embora o consumo de biocombustíveis seja incentivado desde a primeira crise do petróleo, quando o governo instituiu o Proálcool em 1975, apenas em 2005 o biodiesel foi introduzido na matriz energética pela instituição do Programa Nacional de Produção e

${ }^{3}$ O setor de geração de eletricidade e calor é o principal emissor (International Energy Agency, 2012).

${ }^{4}$ A busca por segurança energética vai no sentido de diversificar a matriz com a produção de energia renovável visando a proteção da economia da oscilação do preço internacional do petróleo em tempos de choques de restrição da oferta (decorrentes de estratégias da Organização dos Países Produtores e Exportadores de Petróleo - OPEP e conflitos geopolíticos), da desvalorização cambial e de desequilíbrios nas contas externas.

${ }^{5} \mathrm{O}$ uso da energia renovável que pode contabilizar para o cumprimento da meta e beneficiar-se de subsídios deve atender a alguns padrões de sustentabilidade.

${ }^{6}$ O RFS II também introduz critérios de sustentabilidade que necessitam de ser observados. 
Uso do Biodiesel (PNPB) ${ }^{7}$, que estabeleceu o aumento do seu consumo de forma gradual por meio de percentuais mínimos de mistura obrigatória por volume de diesel ao longo dos anos. O B2 (mistura de 2\% de biodiesel por volume de diesel) foi autorizado em 2005 e tornou-se obrigatório a partir de 2008. O B5, que deveria ter sido introduzido a partir de 2013, foi antecipado e passou a vigorar a partir de 2010. Atualmente vigora o B13 (Associação dos Produtores de Biocombustíveis do Brasil, 2020).

Embora a produção de biodiesel seja relativamente inferior à de etanol no Brasil e nos Estados Unidos, ela é crescente e os Estados Unidos são o maior país produtor, seguido pela Argentina e Brasil (Empresa de Pesquisa Energética, 2013a). A principal matéria-prima empregada em ambos os países é o óleo de soja9, enquanto na União Europeia é o óleo de canola. O bloco constitui-se no principal mercado, contabilizando $55 \%$ da produção mundial. Alemanha, França, Espanha e Itália representam cerca de $63,23 \%$ da produção do grupo, sendo só a Alemanha responsável por 32,53\% em 2011 (European Biodiesel Board, 2013).

A produção do biodiesel em escala industrial é relativamente recente (início dos anos 1990 na União Europeia), mas as pesquisas com óleos vegetais para produção de biocombustível remontam à primeira metade do século XX, com o registro da primeira patente sobre o processo de obtenção do biodiesel em 1937, na Bélgica. As pesquisas em biocombustíveis intensificaramse a partir da primeira crise do petróleo, em 1973, quando a elevação dos preços decorrente da restrição na oferta agravou problemas no balanço de pagamento das economias e revelou uma forte dependência do petróleo e a necessidade de investimentos em energias alternativas.

No contexto de estabelecimento do mercado de biodiesel, a inovação é essencial no desenvolvimento dessa tecnologia para reduzir seu custo de produção, viabilizando-a economicamente. Em Hicks (1932), a inovação é um dos tipos de progresso econômico que aparece como a mudança no processo produtivo que reduz custos de produção ao viabilizar semelhante quantidade produzida a partir de menor quantidade de fatores por alterar seu produto marginal, elevando, assim, a Renda Nacional. Para Hayami \& Ruttan (1985), a inovação envolve processos que geram novidades na ciência, tecnologia, gestão industrial e organização econômica.

Na medida em que o mercado apresenta capacidade limitada de absorção para dado nível de conhecimento científico (potencial inovador), a introdução da inovação ocorre, de fato, na presença de expectativa de lucratividade que, por sua vez, depende de um contexto de expansão da demanda (Schmookler, 1966). Essa abordagem, que dá ênfase aos fatores de mercado que afetam a inovação por alterar sua demanda, está contida na literatura da teoria da inovação induzida, pioneiramente introduzida por Hicks (1932). Este autor deu maior ênfase ao papel da mudança no preço relativo dos fatores que aumenta os custos de produção e, consequentemente, aumenta a demanda por novas tecnologias poupadoras do fator relativamente mais caro.

Nesse caso, pode-se dizer que a tendência de aumento relativo no preço dos combustíveis derivados do petróleo seria acompanhada pelo aumento da demanda de combustíveis renováveis (tecnologia substituta) que induz inovação para viabilizar seu uso pela redução

\footnotetext{
7 O PNPB é um programa que objetiva a "implementação de forma sustentável, tanto técnica, como econômica, da produção e uso do biodiesel, com enfoque na inclusão social e no desenvolvimento regional, via geração de emprego e renda" (Brasil, 2013).

${ }^{8}$ Para teor suficientemente baixo, até $20 \%$, a mistura possui adequabilidade técnica ao motor diesel convencional (Diop et al., 2013), o que viabiliza a difusão de seu consumo.

${ }^{9}$ Embora não represente a matéria-prima com maior rendimento (litros/hectare), seu predomínio se deve, em parte, ao aproveitamento da infraestrutura e resíduos da atividade principal pré-existente de produção de farelo para alimentação animal.
} 
de custos. Assim, a inovação no setor de biodiesel pode ser determinada pelo aumento da demanda induzida pelo aumento no preço do diesel convencional.

Por outro lado, o estabelecimento dos marcos regulatórios observados nos anos 2000 também pode constituir importante fator determinante da inovação tecnológica em biodiesel, pois assegura, em certo grau, demanda para o produto. Já a política fiscal de isenção tributária e/ ou concessão de subsídios pode estimular a inovação na medida em que promove a mudança no preço relativo pela redução de custos no setor. Do lado da oferta, a política nacional de investimento em P\&D também pode determinar a inovação no setor ao aumentar a capacidade tecnológica da qual ele pode se beneficiar.

A atividade inovadora nas economias tem sido mensurada pela emissão de patentes ou publicação de pedido de patente. Relacionados ao biodiesel, os pedidos de patentes apresentaram tendência semelhante nos principais países produtores, sendo incipiente até a década de 1990 e assumindo inflexão positiva a partir do estabelecimento de metas para o consumo e produção de biocombustíveis nos anos 2000, conforme pode ser observado a partir do Instituto Nacional da Propriedade Industrial (2008a, 2008b).

Nesse contexto, em que a inovação é fundamental para a redução do custo de abatimento das emissões de GEE pelo desenvolvimento de energias renováveis, tem-se por objetivo investigar se os fatores de mercado, especialmente a tendência de alta no preço do petróleo, e as políticas públicas regulatória e fiscal afetam positivamente a inovação no setor de biodiesel dos principais países produtores da União Europeia, nos Estados Unidos e Brasil no período de 2000 a 2011. Também pretende-se averiguar se a proporção do gasto do governo em Pesquisa e Desenvolvimento (P\&D) tem influência positiva sobre a inovação no biodiesel.

Dado que o setor de energia constitui força motriz do crescimento econômico de uma nação, é fundamental o entendimento dos determinantes da inovação no biodiesel. A literatura econômica tem se concentrado na avaliação dos determinantes da inovação em diversos tipos de energias. A partir de dados de pedidos de patentes depositados por 25 países de renda elevada no European Patent Office (EPO) no período de 1978 a 2003, Johnstone et al. (2010) verificaram que as políticas em energias renováveis são o principal condutor da inovação em fontes renováveis empregadas na geração de eletricidade.

Já Lanzi et al. (2012), com dados de patentes de 11 países membros da OCDE no período de 1978 a 2008, observaram que o aumento do preço do combustível fóssil eleva a inovação em energias renováveis e a inovação em combustíveis fósseis que tenha objetivo de reduzir emissões. Kruse \& Wetzel (2015) levantaram dados de pedidos de patente de 11 tipos de tecnologias (relacionadas à energia) emitidos no EPO por 26 países da OCDE no período de 1983 a 2009. Seus resultados evidenciam que a mudança no preço da energia tem impacto positivo acerca da inovação relacionada à energia renovável e à eficiência energética em algumas destas tecnologias.

Para o setor de biocombustíveis, especificamente, existem trabalhos que avaliam a inovação no etanol. Em geral, os estudos de Jang \& Du (2013) e Karmarkar-Deshmukh \& Pray (2009) para os Estados Unidos verificam que tanto os fatores de mercado quanto as políticas governamentais de P\&D têm impacto sobre o nível da atividade inovadora no setor. Para o Brasil, o estudo de Freitas \& Kaneko (2012) não explora o papel da política pública em relação à inovação.

Nesta pesquisa, busca-se preencher a lacuna na literatura internacional e nacional no que diz respeito ao estudo dos determinantes da inovação no biodiesel. Esta análise se faz pertinente visto que possibilita o entendimento sobre o modo como a inovação no setor responde aos incentivos econômicos e de política pública, podendo contribuir com a elaboração das políticas ambiental e de segurança energética.

Este artigo tem seu desenvolvimento apresentado em 4 seções, além desta introdução. Na segunda, expõe-se a abordagem teórica que dá suporte ao objetivo apresentado. Na terceira 
seção, são apresentados os dados e a metodologia utilizados. Em seguida, os resultados obtidos e discutidos. Finalmente, têm-se as considerações finais na quinta seção.

\section{Referencial Teórico}

\subsection{Determinantes Demand-pull da Inovação}

Na teoria neoclássica de crescimento econômico, os estudos compreendidos na literatura da inovação induzida constituem a primeira tentativa de explicar o progresso técnico como um processo endógeno. Hicks (1932) apresenta a teoria da inovação induzida, a qual é definida como a inovação resultante da mudança no preço relativo dos fatores. $\mathrm{O}$ autor afirma que a mudança no preço relativo por forças de mercado (oferta dos fatores) aumentará a demanda por novos métodos de produção que sejam menos intensivos no fator relativamente mais caro a fim de reduzir custos de produção.

Desde a publicação de Hicks (1932), Syed Ahmad tem defendido a ideia de que a mudança no preço relativo dos fatores pode influenciar a natureza da inovação pelo aumento de sua demanda. Schmookler (1966) foi pioneiro em enfatizar que quanto maior for o mercado de fato ou potencial, maior será a atividade inovadora direcionada a ele devido à relação positiva entre seu tamanho e lucratividade. Nessa perspectiva, Ahmad (1966) propõe um modelo analítico para o entendimento do fenômeno da inovação (ou invenção ${ }^{10}$ ) induzida nos moldes da abordagem tradicional de estática comparativa.

Enquanto o processo de substituição de fatores é refletido no movimento entre dois pontos sobre a mesma função de produção, o processo de inovação (que permite obter igual quantidade de produto empregando menos fatores de produção) é representado por qualquer tipo de mudança na função de produção ${ }^{11}$. Em vista disso, para um determinado nível específico de produção, a mudança de isoquanta ${ }^{12}$ expressa inovação.

Ahmad (1966) define a Curva de Possibilidade de Inovação (CPI) como a curva envelope que tangencia as alternativas isoquantas (de um dado nível de produto para diferentes funções de produção) em seus pontos de custo mínimo dado o preço relativo dos fatores. Cada CPI refere-se a um nível específico de recursos gastos em Pesquisa e Desenvolvimento (P\&D) representando uma habilidade de inovação. O ponto em que a isocusto ${ }^{13}$ tangencia a CPI determinará a isoquanta e a função de produção da firma até a próxima inovação. A isoquanta determinada dessa forma será mais poupadora de um fator quanto maior for seu preço relativo.

Na Figura 1, é ilustrado o processo de inovação induzida no mercado de combustíveis líquidos (em que o biodiesel é uma alternativa tecnológica substituta ao diesel) pelo mecanismo analítico proposto por Ahmad (1966). Para os períodos 0 e 1, $C_{0}$ e $C_{I}$ são curvas CPI neutras ${ }^{14} \mathrm{e}$ $I_{0}, I_{l}$ e $I_{l}^{\prime}$ são isoquantas (de um dado nível de produto) que representam funções de produção

${ }^{10}$ No início de seu trabalho, o autor esclarece que os termos "inovação" e "invenção" são indistintamente utilizados na literatura que aborda a mudança técnica estimulada pela mudança no preço relativo dos fatores.

${ }^{11}$ Tal conceito pressupõe que as firmas operam sobre a Fronteira de Possibilidade de Produção (FTP), curva que representa o máximo de produção que pode ser alcançado a dada tecnologia e fatores de produção disponíveis, ou seja, pressupõe que as firmas empregam os fatores de forma eficiente.

${ }^{12}$ Cada curva isoquanta representa um nível de produção e cada conjunto de isoquantas está associado uma função de produção específica.

${ }^{13}$ Representa as diferentes combinações de dois fatores que podem ser empregadas a um custo total constante.

${ }^{14}$ Para isolar o efeito da mudança no preço dos fatores na natureza do processo inovador, pressupõe-se que a CPI seja neutra, ou seja, a dado preço relativo, a $n$-ésima inovação usa a mesma proporção de fatores que era empregada na (n-1)-ésima inovação. Isto posto, duas isoquantas sobre duas CPI neutras também serão neutras para cada razão de preço. 
da mistura dos combustíveis para diversas combinações (proporção do volume) do biodiesel com o diesel.

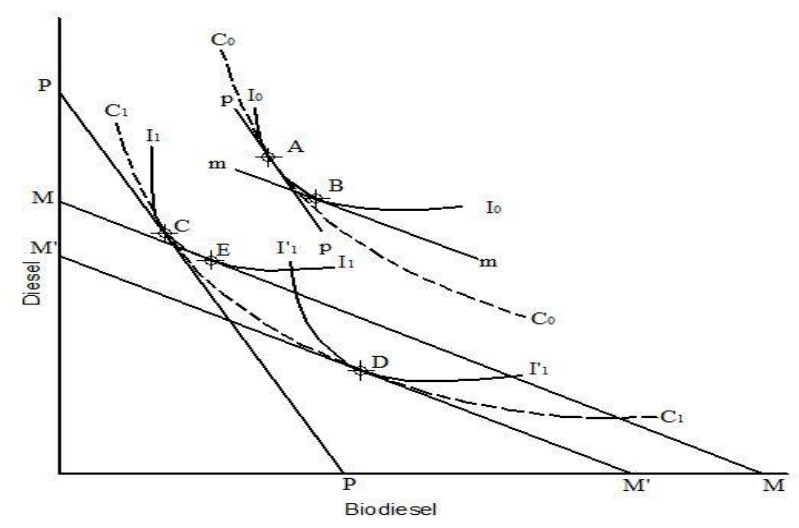

Figura 1 - Inovação induzida pelo aumento relativo no preço do diesel derivado do petróleo. Fonte: Elaboração própria.

No tempo 0 , a isoquanta $I_{0}$ representa uma combinação específica de biodiesel com diesel que minimiza custos de produção do combustível no ponto ${ }_{A}$ (tangente à $C_{0}$ ) dada a razão dos preços $p p$. Com a tendência de elevação no preço do diesel, a razão dos preços pode ser representada pela isocusto $\mathrm{mm}$. $\mathrm{O}$ aumento relativo no preço do diesel aumenta a demanda do biodiesel, tecnologia substituta, para fins de minimização de custos. Logo, no período 1 , após o deslocamento da isoquanta, $i_{l}^{\prime}$ minimiza custos no ponto ${ }_{D}$ (tangente à $C_{l}$ ). A distância $M M \cdot$ representa o ganho adicional pelo desenvolvimento de inovação poupadora de diesel (ao invés de inovação poupadora de biodiesel - ponto $E$ na isoquanta $I_{l}$ ).

Hayami \& Ruttan (1985) apoiam-se nesse modelo desenvolvido por Ahmad (1966) para explicar as diferenças na produtividade e na trajetória de desenvolvimento agrícola dos países. A diferença no preço relativo dos fatores, sinalizando a diferença na dotação relativa dos países, explica a existência de viés em suas trajetórias de inovação poupadora de fator distinto. Ressaltam que mudança no preço relativo dos fatores induzirá a inovação a uma trajetória eficiente desde que os preços no mercado sinalizem, corretamente, a demanda e a oferta do produto ou insumo.

Para prosseguir nesta seção teórica, faz-se necessário expor algumas considerações em relação ao estado da arte sobre as teorias econômicas que abordam os determinantes da inovação. Pari passuà corrente neoclássica, estudos baseados em pressupostos não ortodoxos foram desenvolvidos por Schumpeter (1939) e aprofundados por seus seguidores, chamados neoschumpeterianos ou evolucionários. Esses estudos questionam, sobremaneira, a ênfase no papel da demanda e da mudança no preço relativo dos fatores dada pela abordagem demand-pull que subordinou o efeito da capacidade científica e tecnológica, fator que atua sobre a inovação pelo lado da oferta. Com base em Rosenberg (1974), as inovações não são igualmente possíveis (ou custosas) nas diferentes indústrias em razão de existir diferenças no estágio de desenvolvimento dos diversos campos científicos e tecnológicos. Para Dosi (1982), os paradigmas tecnológicos ${ }^{15}$ estabelecem as oportunidades tecnológicas no que tange às inovações, ou seja, moldam e limitam a taxa e a direção da mudança técnica. Um paradigma tecnológico estabelece o padrão de solução de problemas tecnológicos em cada indústria e

${ }^{15} \mathrm{Em}$ que a tecnologia define-se como um conjunto de partes do conhecimento codificado (teórico) e do conhecimento tácito (know-how). 
determina o campo de pesquisa, os problemas, os procedimentos e as tarefas. Apesar de não fundamental, ressalva-se que a influência do mercado não deve ser desprezada (Mowery \& Rosenberg, 1979) ${ }^{16}$.

Em vista disso, para que se possa verificar como se dá a relação entre o preço do petróleo e as políticas públicas com a inovação no biodiesel, é reconhecida a necessidade de se incorporar fatores que afetam a inovação pelo lado da oferta. Portanto, apresenta-se a abordagem technology-push para dar suporte teórico à importância desses fatores.

\subsection{Determinantes Technology-push da Inovação}

Para que seja possível analisar e obter a relação do preço do combustível fóssil e das políticas públicas com a inovação no biodiesel, deve-se mensurar também a influência da capacidade tecnológica sobre a atividade inovadora. A capacidade tecnológica refere-se ao grau de "facilidade" (o quanto é custosa) da inovação na indústria, dado o preço do insumo no mercado (Cohen \& Levin, 1989). Em outras palavras, espera-se que quanto maior seja o nível de conhecimento acumulado em uma firma, maior será sua habilidade em desenvolver novas tecnologias e menores o esforço e custo dispendidos no processo.

Os estudos seminais na literatura da inovação induzida estão centrados no papel das forças de mercado que afetam a inovação por alterar sua demanda. Embora mencionada e, em alguns casos, mensurada, a capacidade tecnológica que afeta a inovação pelo lado da oferta é tratada como fator exogenamente determinado. A esse respeito, Cohen \& Levinthal (1989) propõem um modelo teórico que explica a geração do conhecimento tecnológico da firma endogenamente ${ }^{17}$. Ao simplificar seu modelo ${ }^{18}$ assumindo que a capacidade tecnológica da firma se refere ao conhecimento tecnológico e científico gerado e acumulado internamente ${ }^{19}$, pode-se mostrar que o aumento da capacidade tecnológica ou do estoque de conhecimento tem efeito positivo sobre o nível ótimo de inovação da firma.

Inicialmente, pressupõe-se a existência de $n$ firmas atuando na indústria com uma política simétrica de inovação. Cada firma escolhe seu nível de inovação para maximizar seu lucro tomando o nível de inovação dos $n-1$ competidores como dado no mercado.

Considere que adições ao estoque de conhecimento científico e tecnológico sejam representadas por $_{e_{i}}$ :

$e_{i}=$ inovação $_{i}$

em que o conhecimento tecnológico é função da própria inovação desenvolvida pela firma $i$.

Nesta pesquisa, ao utilizar o método do inventário perpétuo para mensurar o estoque de conhecimento, (1) equivale a (2):

$E_{i, t-1}=$ inovação $_{i, t-1}+E_{i, t-2}$

${ }^{16} \mathrm{Na}$ corrente evolucionária, o mercado constitui um dos mecanismos de seleção ex-post da inovação dentre opções de trajetórias.

${ }^{17} \mathrm{~A}$ partir deste modelo, os autores pretendem demonstrar que o investimento em $\mathrm{P} \& \mathrm{D}$, além de possível medida de inovação, determina o grau de aprendizado ou capacidade de absorção da firma do conhecimento disponível externamente.

${ }^{18} \mathrm{O}$ modelo considera que o aumento no estoque de conhecimento de uma firma depende do conhecimento gerado nas outras firmas e nas outras indústrias, além do próprio conhecimento gerado internamente.

${ }^{19}$ Analogamente, nesta pesquisa, assume-se que a capacidade tecnológica de cada país refere-se ao conhecimento tecnológico disponível internamente em cada país. 
$\Delta E_{i, t-1}=$ inovação $_{i, t-1}$

A função de lucro bruto em cada firma é representada como segue:

$\Pi^{i}=\Pi_{e_{i}}^{i} \cdot\left(e_{i}\right)$

em que se pressupõe que $e_{i}$ aumenta o lucro bruto da firma a taxas decrescentes, ou seja, $\Pi_{e_{i}}^{i}>0$ e $\Pi_{e_{e}, e_{i}}^{i}<0$.

A função do retorno marginal da inovação de cada firma é obtida pela diferenciação de (3) em relação à inovação $o_{i}$ :

$R \equiv \frac{\partial \Pi^{i}}{\partial \operatorname{inovaçãoo~}_{i}} \equiv \Pi_{e_{i}}^{i}$

Resolvendo (4) para a condição de maximização de primeira ordem, $\Pi_{e_{i}}^{i}=0$, para as $n$ firmas simultaneamente, obtém-se o nível de equilíbrio de inovação de cada firma inovação* .

Assumindo que a capacidade tecnológica que mensura o grau com que o novo conhecimento e melhora o desempenho tecnológico de manufaturar processos e produtos na firma seja representada pela variável $f$, pode-se mostrar o efeito da capacidade tecnológica sobre o nível

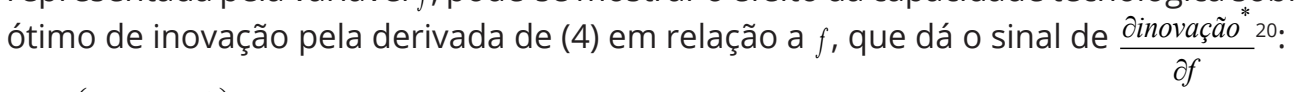

$\sin a l\left(\frac{\partial i n o v a c ̧ a o^{*}}{\partial f}\right)=\sin a l\left(\prod_{e_{i}, f}^{i}\right)=\sin a l\left(R_{f}\right)$

em que $\prod_{e_{i}, f}^{i}>0$, pois pressupõe-se que quanto mais o conhecimento melhora o desempenho tecnológico, mais ele aumenta o lucro. Dessa forma, é possível visualizar que $\frac{\text { inovação }^{*}}{\partial f}>0$, ou seja, o crescimento da capacidade tecnológica ou estoque de conhecimento aumenta o nível ótimo de inovação na firma, já que aumenta seu lucro ao reduzir custos no desenvolvimento de novas tecnologias.

Embora em comunhão com a corrente evolucionária na admissão da existência de atividade inovadora independente da demanda, a abordagem technology-push é questionada pela linearidade que assume na relação ciência-tecnologia-produção e pelo estabelecimento limitado de fontes de conhecimento.

Ciente das limitações, as abordagens demand-pulle technology-push apresentam-se adequadas aos objetivos desta pesquisa, haja vista que a primeira teoria descreve especificamente o papel da mudança no preço relativo de petróleo e biodiesel e da demanda "assegurada" pela introdução de políticas públicas ${ }^{21}$ no setor sobre a inovação.

\subsection{Inovação no Biodiesel e Políticas Públicas}

As políticas de produção e uso de biocombustíveis objetivam reduzir o nível de emissões de GEE no intuito de atender a demanda mundial pela desaceleração do processo de aquecimento global e, adicionalmente, diminuir a dependência de energias não renováveis, gerando emprego e renda internamente nas economias dos países importadores (líquido) de petróleo. Segundo

${ }^{20}$ Para qualquer parâmetro $s$, pode ser demonstrado que o sinal de dinovação ${ }^{*} / \partial s$ é igual ao sinal de $R_{s}$. A prova está disponível em um apêndice técnico daqueles autores.

${ }^{21}$ A atuação do Estado na teoria neoclássica, com a introdução de políticas públicas, tem motivação diferente da teoria evolucionária. Para maiores detalhes ver Costa (2016). 
a Food and Agriculture Organization (Food and Agriculture Organization of the United Nations, 2008), a redução das emissões de GEE no ciclo de vida dos biocombustíveis de primeira-geração pode variar de $20 \%$ a $60 \%$ relativamente ao combustível fóssil conforme matéria-prima, local e tecnologias de produção22.

Para efetivar o objetivo destas políticas, os governos lançam mão de instrumentos de política fiscal e regulatória. Os principais instrumentos de incentivo fiscal referem-se à redução ou isenção de impostos e à concessão de subsídios, enquanto os de política de regulação dizem respeito à definição de meta de produção ou consumo e ao estabelecimento de percentual mínimo obrigatório ou voluntário de biodiesel no diesel vendido ${ }^{23}$.

Espera-se que ambos os tipos de política sejam determinantes demand-pull, estimulando a atividade de inovação no biodiesel pelo lado da demanda, já que os instrumentos da política fiscal atuam reduzindo os custos de produção e, consequentemente, o preço do biodiesel em relação ao diesel. Ainda, aqueles instrumentos da política regulatória asseguram demanda ao produtor aumentando, dessa forma, o retorno e a demanda da inovação no biodiesel.

Adicionalmente, espera-se que a política nacional de investimento em P\&D seja um determinante do tipo technology-push aumentando a capacidade tecnológica nacional, da qual o setor de biodiesel pode se beneficiar. Os governos atuam diminuindo os custos da inovação pela própria pesquisa que desenvolvem, pela disseminação do conhecimento tecnológico e pelo subsídio à pesquisa privada (Cohen \& Levin, 1989).

\section{Metodologia}

Para mensurar inovação, opta-se pelo uso de patente, pois mensura o resultado ou produto observado no processo inovador que poderá entrar no sistema econômico modificando as relações de produção. A escolha é, também, corroborada pelos diversos estudos empíricos que validam o seu uso pela forte correlação que apresenta com a atividade de P\&D (Griliches, 1990).

O número de patentes emitidas por um país a cada ano é uma variável não negativa e discreta, caracterizando-se, assim, como uma variável de contagem. Desta forma, apresenta-se um método econométrico adequado às propriedades específicas deste tipo de dados.

\subsection{Modelo de Poisson em Painel de Efeito Fixo}

O estimador de Mínimos Quadrados Ordinários (MQO), baseado no pressuposto de erros normalmente distribuídos, obtém a esperança condicional da variável dependente como uma função linear dos parâmetros. Na medida em que dados do tipo contagem não são normalmente distribuídos, a aplicação do MQO demonstra ajuste inadequado do modelo linear, que conduz a valores estimados negativos da variável dependente.

Uma alternativa eficaz que garante valores previstos sempre positivos é aplicar o estimador de Método dos Momentos Generalizados ( $G M M$ ) baseado na especificação da variável dependente de contagem como uma função exponencial:

$\mu_{i t}=E\left[y_{i t} / x_{i t}, \ldots, x_{i 1}\right]=E\left[y_{i t} / X_{i}^{(t)}\right]=\alpha_{i} \lambda_{i t}$

${ }^{22}$ Embora os biocombustíveis emitam menos GEE em seu ciclo de vida, quando se consideram os efeitos diretos e indiretos do aumento de sua produção sobre o uso da terra, as emissões podem ser maiores para algumas matériasprimas e sistemas de produção (Food and Agriculture Organization of the United Nations, 2008).

${ }^{23}$ Para detalhes, consultar International Energy Agency (2015). 
em que a esperança ou média condicional de $y_{i t}$ é positiva, $\mu_{i t}>0 ; \exp \left(x_{i t} \beta\right)=\lambda_{i t} ; x_{i t}^{\prime}$ é um vetor de $K$ variáveis explicativas; a heterogeneidade não observada ou o efeito específico de cada indivíduo, $\alpha_{i}$, é correlacionada com as variáveis explicativas, $E\left(x_{i t} \alpha_{i}\right) \neq 0$. Admite-se a presença de regressor predeterminado, $E\left(x_{i t} u_{i s}\right)=0$ quando $s \geq t$, em que realizações presentes e futuras do erro são não correlacionadas com o vetor de variáveis explicativas.

Logo, tem-se o seguinte modelo de efeito fixo:

$y_{i t}=\alpha_{i} \exp \left(x_{i t}^{\prime} \beta\right)+u_{i t}$

Para obter estimativas consistentes para (7), uma alternativa diferenciação foi proposta por Chamberlain (1992):

$q_{i t}(\theta)=\frac{\lambda_{i, t-1}}{\lambda_{i t}} y_{i t}-y_{i, t-1}=\frac{\lambda_{i, t-1}}{\lambda_{i t}} u_{i t}-u_{i, t-1}$

em que $\lambda_{i t}=\lambda_{i t}(\theta)$.

Sob (6), tem-se:

$E\left[q_{i t}(\theta) / z_{i t}\right]=0$

em que os instrumentos $x_{i, t-1}, x_{i, t-2} \ldots$, contidos em $z_{i t}$, são predeterminados ${ }^{24}$.

Dessa forma, quando o modelo é exatamente identificado, com o número de instrumentos igual ao número de parâmetros estimados, o estimador $G M M$ resolve a seguinte condição de momento:

$\sum_{i=I t=1}^{N} \sum_{i t}^{T} z_{i t} q_{i t}(\theta)=0$

Conforme Cameron \& Trivedi (2015), é comum que o número de instrumentos seja superior ao total de parâmetros. Portanto, o estimador $G M M$ de $\beta$ em dois passos minimiza:

$\left(\sum_{i=1}^{N} \sum_{t=1}^{T} z_{i t} q_{i t}(\theta)\right)^{\prime} W_{N}\left(\sum_{i=1}^{N} \sum_{t=1}^{T} z_{i t} q_{i t}(\theta)\right)=0$

em que $W_{N}$ é uma eficiente matriz de peso.

\subsection{Base de Dados}

\subsubsection{Patentes}

Quando se opta pelo uso de dados de patentes, é preciso considerar alguns aspectos que as caracterizam como uma medida imperfeita. Primeiramente, a duração do processo para a concessão de uma patente pode variar entre os países conforme as regras e características da instituição que concede tal direito. Consequentemente, para captar explicitamente a existência da defasagem temporal entre o pedido de uma patente e a sua emissão, classificam-se as

${ }^{24}$ É importante notar que este estimador não impõe qualquer restrição sobre a variância. Assim, não pressupõe equidispersão (variância igual a média). 
patentes conforme a data de depósito do pedido que capta mais proximamente o período em que a inovação é desenvolvida ${ }^{25}$.

Também deve-se ressaltar outra característica que diz respeito às regras do instituto nacional de patentes. Em específico, para alguns países podem ser requisitadas patentes múltiplas para uma mesma inovação que seria coberta por uma única patente em outra nação (Johnstone et al., 2010). Para contornar esta característica que dificulta a comparação do número de patentes entre os países, os dados sobre patentes no biodiesel são reduzidos à família de patentes nesta pesquisa. Uma família de patente consiste no conjunto de pedidos e/ou patentes publicados em uma ou em diferentes nações para proteger uma ou diversas inovações que dividem um mesmo aspecto (World Intellectual Property Organization, 2013). Evita-se, assim, o potencial problema de dupla contagem.

Deste ponto, segue a descrição do procedimento para elaboração da base de dados de patentes no biodiesel. A partir de uma sequência de estudos do Instituto Nacional de Propriedade Industrial (INPI) publicados entre 2008 e $2012^{26}$, que identificaram e disponibilizaram o número de pedidos de patentes relacionadas ao biodiesel para o Brasil, Estados Unidos e União Europeia, foi possível buscar e verificar a existência ou não de correspondente patente emitida.

Para averiguar a existência ou não de correspondente patente emitida a partir desses números, buscou-se primeiramente cada registro do número de publicação no Espacenet (um serviço gratuito de busca online na base de dados do EPO). As informações bibliográficas disponíveis e de interesse na pesquisa são: número da publicação do pedido e da patente; código alfabético associado; data do depósito do pedido; registros de prioridade ${ }^{27}$; país de residência do depositante.

Na próxima etapa, foi realizada a análise dos códigos alfabéticos e mantiveram-se na lista apenas aqueles que identificavam a primeira publicação do pedido e da patente (quando existia) para que não ocorresse duplicação na coleta de dados, visto que a um mesmo registro poderiam estar associadas mais de uma publicação referente às diversas fases do processo de obtenção de uma patente ${ }^{28}$.

Em seguida, foi identificado o registro dos pedidos (e correspondente patente) que pertenciam à mesma família "simples" (aquela que conjuga de semelhante conjunto de documentos prioridade) em "also published as". Identificadas as famílias, o documento foi alocado para o país que tem a nação de residência do depositante coincidente com a nação do documento prioridade.

A partir dessa base de dados sobre família de pedidos de patentes relacionadas ao biodiesel, foram selecionadas, para a amostra de interesse, as patentes (famílias) no biodiesel depositadas por residente no país ${ }^{29}$ e classificadas com a data do depósito do pedido entre 2000 e 2011, período que envolve o início da produção de biodiesel em escala industrial na maioria dos países produtores. Nesse ponto, é possível identificar, dentre os maiores produtores de biodiesel na

${ }^{25}$ Esta prática é comum na literatura empírica. Dentre muitos, Popp (2002) e Karmarkar-Deshmukh \& Pray (2009) são alguns exemplos.

${ }^{26}$ Em "Referências", os estudos compõem as séries do INPI de mapeamento tecnológico (Instituto Nacional de Propriedade Industrial, 2008a, 2008b) e alerta tecnológico (Instituto Nacional de Propriedade Industrial, 2008c, 2009a, 2009b, 2010a, 2010b, 2011a, 2011b, 2012).

${ }^{27} \mathrm{~A}$ prioridade sobre determinada matéria parte de uma inovação é um direito que garante ao depositante o requisito novidade para um segundo pedido de patente dentro de um intervalo de 12 meses a partir da data do primeiro depósito.

${ }^{28} \mathrm{~A}$ lista com os tipos de códigos, intitulada " concordance of kind code", é periodicamente atualizada e disponibilizada no site do EPO (European Patent Organisation, 2020).

${ }^{29} \mathrm{O}$ país de residência do depositante representa a origem do documento e é identificado, nessa pesquisa, pelo país do primeiro depositante (muitos documentos apresentam mais de um depositante). 
União Europeia, que os países com maior nível de atividade inovadora são: Alemanha, França, Espanha, Reino Unido, Itália, Áustria e República Checa.

Por fim, cabe observar, que não foram encontrados alguns dos registros disponibilizados naqueles estudos do INPI ${ }^{30}$. Além disso, note que, na sequência, as famílias de patentes são referenciadas apenas como patentes para simplicidade na exposição.

\subsubsection{Variáveis Explicativas}

Para obter a demanda do mercado em cada país, empregou-se a taxa anual (\%) de crescimento do consumo de biodiesel, cresCons $_{i^{\prime}}$ já que permite captar a expectativa de crescimento futuro do mercado e, dessa forma, a expectativa de retorno da inovação. Na unidade de (mil) barris ao dia, os dados sobre consumo de biodiesel estão disponíveis no U.S. Energy Information Administration (2015, EIA).

$\mathrm{Na}$ ausência de uma medida do preço do diesel convencional que fosse comparável entre os países, utiliza-se o preço do petróleo, Ppetro $_{i t}$, como sua proxy. A série de dados do preço internacional do petróleo foi coletada no International Monetary Fund (2015, IMF), onde está disponível em dólar por barril (US\$/barril) ${ }^{31}$. Para deflacionar e obtê-la em valores reais de 2005, utilizou-se o Consumer Price Index - All Urban Consumers (CPI), coletado no United States Department of Labor (United States Department of Labor Bureau of Labor Statistics, 2015). De modo que fosse obtida a necessária variabilidade nos indivíduos do painel (países) para a adequada execução do método, ponderou-se o preço $(100=2005)$ desta commodity por sua taxa de dependência externa. Essa taxa é obtida pela razão entre o total de petróleo importado e o total consumido no ano $2000^{32}$. Assume-se, portanto, que o efeito da mudança no preço do petróleo seja crescente com a dependência externa. Cada série está disponível em (mil) barris ao dia e foi coletada no U.S. EIA (U.S. Energy Information Administration, 2015).

Para mensurar uma das variáveis que representam a política pública, é utilizada a participação (\%) do gasto bruto em P\&D financiado pelo governo em relação ao gasto bruto doméstico total em P\&D, txP \& Dgov $v_{i t}$. Os dados sobre o gasto bruto em P\&D financiado pelo governo e o gasto bruto doméstico total em P\&D, disponíveis em (mil) unidade monetária local foram coletados na United Nations Educational, Scientific and Cutural Organization (2015, UNESCO). Na medida em que dados sobre gasto bruto em P\&D financiado pelo governo da Itália somente estão disponíveis a partir de 2005, o país teve que ser retirado da amostra.

Para mensurar a capacidade tecnológica de inovação em biodiesel de um país, calculase o estoque de conhecimento em biodiesel, $E_{i, t-1}{ }^{33}$, pelo método do inventário perpétuo: $E_{i, t-1}=$ Pat total $_{i, t-1}+(1-\delta) E_{i, t-2}$, em que a taxa de depreciação $\delta$ mensura a velocidade com que 0 conhecimento torna-se obsoleto. O valor de $10 \%$, ou seja, $\delta=0,10$, é comumente assumido na literatura ${ }^{34}$. Assim, para o ano $t=2$, por exemplo, o estoque é $E_{i, 1}$ e mensura o conhecimento acumulado até $o$ ano $t=1$, que equivale à soma do total de patentes emitidas em biodiesel no país (por depositante residente ou não) no ano $t=1$, Pat total , à $90 \%$ do estoque no ano $t=0,0,9 E_{i, 0}$.

${ }^{30}$ Os números destes registros são apresentados no APÊNDICE.

${ }^{31} \mathrm{~A}$ série de dados utilizada refere-se ao Crude Oil (petroleum), Dated Brent, light blend 38 API, fob U.K.

${ }^{32} \mathrm{~A}$ taxa de dependência externa é relativamente constante ao longo dos anos da amostra.

${ }^{33}$ Ao observar a construção desta variável, é importante ressaltar que o uso do subscrito $t-1$ refere-se à nomenclatura apenas. Não se trata de um termo defasado de uma variável $E_{i t}$ (que não existe neste modelo).

${ }^{34}$ Ver Verdolini \& Galeotti (2011) e Kruse \& Wetzel (2015). 
Nesse método, o estoque no período inicial $E_{i, 0}$ é obtido pela seguinte fórmula: $E_{i, 0}=$ Pat $t_{i, 0}^{\text {total }} /(\delta+\bar{g})$

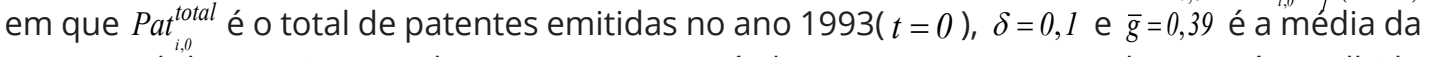
taxa anual de crescimento das patentes no período 1986 - 1992. O ano de 1993 é escolhido porque reflete o padrão observado no total de patentes emitidas em cada país durante o período pré-amostral, 1981-1999. A distância entre o ano $t=0$ escolhido e o período inicial da amostra de fato utilizada tem o objetivo de minimizar o efeito da forma com que $E_{i, 0}$ é calculado.

Apresentam-se resumidamente as informações sobre a fonte e unidade de medida das variáveis do modelo na Tabela 1 para facilitar sua localização.

Tabela 1- Descrição das variáveis, fonte e unidade de medida

\begin{tabular}{|c|c|c|c|}
\hline Variável & Descrição & Unidade & Fonte \\
\hline Pat $_{i t}$ & $\begin{array}{l}\text { Patentes relacionadas ao } \\
\text { biodiesel }\end{array}$ & Número de patentes & Espacenet (EPO $\left.{ }^{1}\right)$ \\
\hline cresCons $_{i t}$ & $\begin{array}{l}\text { Taxa anual de crescimento do } \\
\text { consumo de biodiesel }\end{array}$ & $(\%)$ & $\mathrm{EIA}^{2}$ \\
\hline Ppetro $_{i t}$ & $\begin{array}{l}\text { Preço do Petróleo (ponderado } \\
\text { pela taxa de dependência externa } \\
\text { de 2000) }\end{array}$ & US $\$ /$ barril & $\mathrm{IMF}^{3}$ \\
\hline$t x P \& D g o v_{i t}$ & $\begin{array}{l}\text { Participação do gasto bruto em } \\
\text { P\&D financiado pelo governo no } \\
\text { total }\end{array}$ & $(\%)$ & UNESCO 4 \\
\hline$E_{i \ddot{\zeta}-}$ & Estoque de patentes & $\begin{array}{l}\text { Número acumulado de } \\
\text { patentes em biodiesel }\end{array}$ & Espacenet (EPO) \\
\hline
\end{tabular}

Fonte: Elaboração própria. Notas: ${ }^{1}$ European Patent Office; ${ }^{2}$ Energy Information Administration; ${ }^{3}$ nternational Monetary Fund (2015); ${ }^{4}$ Únited Nations Educational, Scientific and Cutural Organization (2015).

\subsection{Modelo Empírico}

Com o suporte da teoria sobre inovação e conhecida a formulação das variáveis, é possível especificar em (9) a forma funcional do modelo empírico estimado pelo método econométrico apresentado na Equação 7:

Pat $_{i t}=\alpha_{i} \exp \left(\beta_{1}\right.$ cresCons $_{i t}+\beta_{2}$ Ppetro $_{i t}+\beta_{3}$ txP \& Dgov $_{i t}+\beta_{4}$ politica $\left.+\beta_{5} E_{i, t-1}+\beta_{6} t\right)+u_{i t}$

em que $P a t_{i t}$ é o número de patentes (famílias) no biodiesel emitidas no país $i$ no ano, $t$, de depósito do pedido feito por residente; $\alpha_{i}$ representa características não observadas que são específicas de cada país; cresCons $_{i t}$ é taxa anual (\%) de crescimento do consumo de biodiesel; Ppetro $_{i t}$ é o preço do petróleo (variável proxy do preço do diesel); txP\&Dgov ${ }_{i t}$ é a participação (\%) do gasto bruto em P\&D financiado pelo governo em relação ao gasto bruto doméstico total em P\&D; ${ }_{i, t-1}$ é o estoque de conhecimento, e $u_{i t}$ é o termo de erro aleatoriamente distribuído.

Outra forma de capturar o efeito da política pública é pela inserção da variável política. Essa é uma variável dummy que recebe valor 1 nos anos em que se observa, simultaneamente, a existência de política fiscal (de redução/isenção tributária ou concessão de subsídio) e de política regulatória (com estabelecimento de metas quantitativas de consumo ou produção). Nos demais anos, a variável assume valor 0 . Ainda, é incluída a variável tendência temporal $t$ para captar o efeito daqueles fatores não observados que variam somente ao longo do tempo como a instituição de normas no processo de obtenção de patente comuns aos signatários da Convenção de Paris. 
Espera-se que todas as variáveis explicativas tenham coeficientes $\beta_{k}$ com sinal positivo e estatisticamente significativos. Para estimar a Equação 9, o estimador apresentado a lineariza pela aplicação do logaritmo neperiano reportando coeficientes para o seu formato log-linear. Portanto, cada coeficiente $\beta_{k}$ estimado mensura a semielasticidade, dito de outro modo, o efeito da mudança de uma unidade da variável explicativa sobre as patentes no biodiesel em termos percentuais.

Já o efeito marginal é obtido em (10):

$E M_{i t k} \equiv \frac{\partial E\left[y_{i t} / x_{i t}, \alpha_{i}\right]}{\partial x_{i t k}}=\alpha_{i} \exp \left(x_{i t}^{\prime} \beta\right) \beta_{k}=\beta_{k} E\left[y_{i t} / x_{i t}, \alpha_{i}\right]$

em que $\beta_{k}$ é o coeficiente da $k$-ésima variável.

\section{Resultados}

\subsection{Patentes}

Ao longo dos 12 anos foram emitidas 530 patentes em biodiesel nos 8 países da amostra, 0 que representa uma média anual de aproximadamente 44 patentes emitidas pelos principais produtores. Pela análise da Figura 2a, verifica-se que a inovação nos principais países produtores e inovadores durante o período de 2000 a 2011 cresceu quase ininterruptamente até 2005, a partir do qual apresenta tendência decrescente alcançando, depois de 2008, um nível de inovação inferior àquele do início do período. Essa tendência poderia ser explicada pela natureza do registro dos dados de patentes executado na pesquisa. É importante ressaltar que o levantamento de patentes publicadas vai até o ano de $2015^{35}$ e que elas foram classificadas segundo as datas dos pedidos, registrados até 2011. Logo, os menores números observados a partir de 2009 devem-se ao fato de que as possíveis patentes decorrentes de pedidos registrados a partir desse ano tenham sido publicadas depois de 2015, dada a existência de defasagem temporal entre o início e a conclusão do processo de obtenção de patente, que pode ultrapassar 2 anos a depender do instituto nacional.

Ao passar para o nível da análise de cada país (Figura 2b), nota-se grande discrepância na inovação do setor, pois enquanto os Estados Unidos foram responsáveis pela emissão de 381 patentes, a soma de patentes no restante dos países equivale a somente 149, das quais 7 constituem a soma daquelas emitidas por Áustria e República Checa. Observa-se que apenas os Estados Unidos e a Alemanha superam a média de aproximadamente 66 patentes por país neste período.

Os Estados Unidos, então, são responsáveis por mais de 70\% da inovação desenvolvida em biodiesel no período e são seguidos pela Alemanha que, emitindo 86 patentes, contribuiu em 16\% para a inovação no setor. Áustria e República Checa não alcançam 1\% do total (Figura 2c).

As patentes consideradas nacionais são aquelas depositadas no instituto nacional por depositante residente neste país em razão de representarem a atividade inovadora desenvolvida internamente sob os aspectos específicos da economia nacional. Quando se comparam as patentes em biodiesel depositadas por residente no país em relação ao total de patentes em

${ }^{35}$ Último ano da coleta de dados. 
biodiese ${ }^{36}$ por residente e não residente (Figura $2 \mathrm{~d}$ ), verifica-se que é alta a inserção estrangeira de patentes em biodiesel na maioria dos países, dado que a taxa de patentes nacionais é inferior a $50 \%$ para 5 países. No Brasil, do total de patentes em biodiesel, apenas pouco mais de $30 \%$ foram depositadas por residente no país. Na Áustria, este percentual não alcança os $10 \%$. Contrariamente, na Alemanha e França, é predominante a inovação em biodiesel desenvolvida por residente no país, pois em torno de $80 \%$ das patentes são nacionais. Em seguida, Estados Unidos apresentam taxa de patentes nacionais superior a $70 \%$.

Note que a análise acima é baseada na quantidade absoluta de patentes emitidas. Para averiguar a dimensão da inovação em biodiesel dentro de cada país, é preciso executar uma análise comparativa que considere o efeito da propensão a patentear de cada país no respectivo setor de biodiesel. Desse modo, é válido analisar a taxa de emissão de patentes em biodiesel em relação ao total de patentes em todas as áreas do conhecimento depositadas por residente que representa o nível de atividade inovadora do país.

(a)
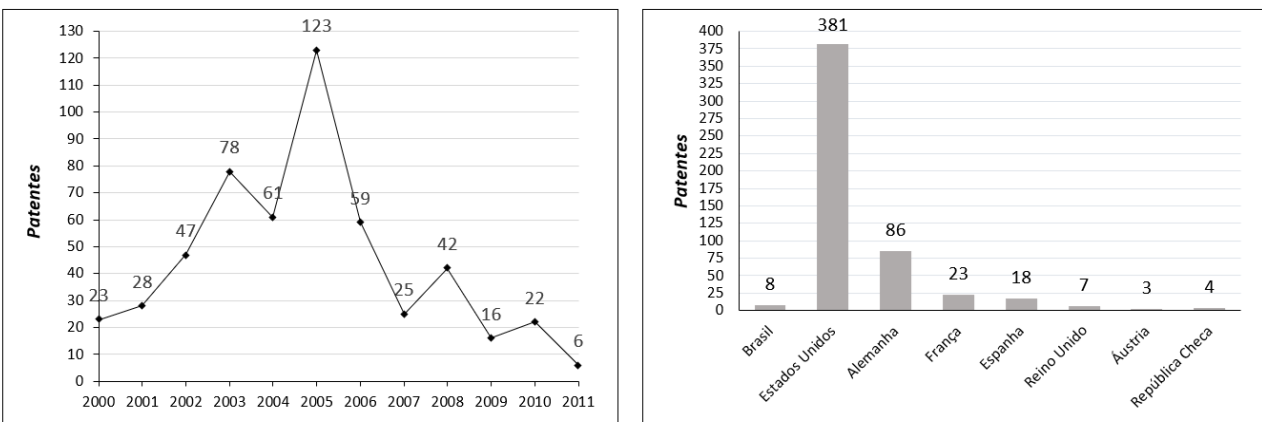

(c)
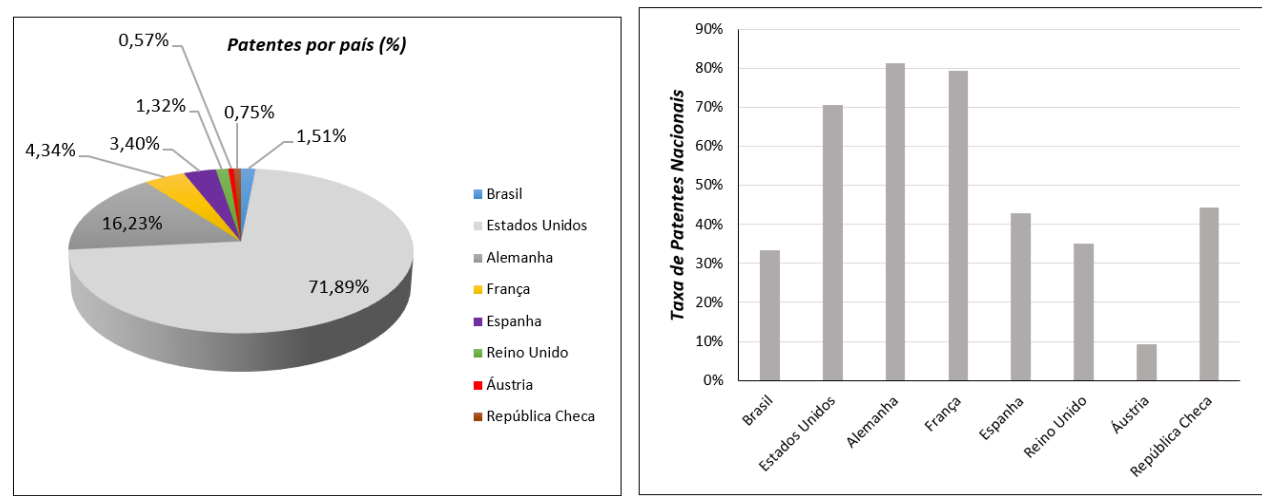

Figura 2 - Estatísticas descritivas sobre os dados de patentes em biodiesel. Fonte: Elaboração própria.

Neste sentido, pela análise da Figura 3, é possível perceber que o Brasil se destaca como a nação mais intensiva em patentes em biodiesel, haja vista que elas contabilizam 0,25\% do total de patentes no país. É seguido por República Checa, Espanha e Alemanha, respectivamente. Deste lado da análise, os Estados Unidos assumem as últimas posições, sendo menos intensivos na inovação em biodiesel, com uma taxa de patentes em biodiesel inferior a 0,05\%.

${ }^{36}$ Essa taxa é calculada com dados sobre o total de patentes, não de famílias de patentes, pois a análise em termos relativos elimina aquele efeito apontado por Johnstone et al. (2010), descrito na subseção "Base de Dados". 


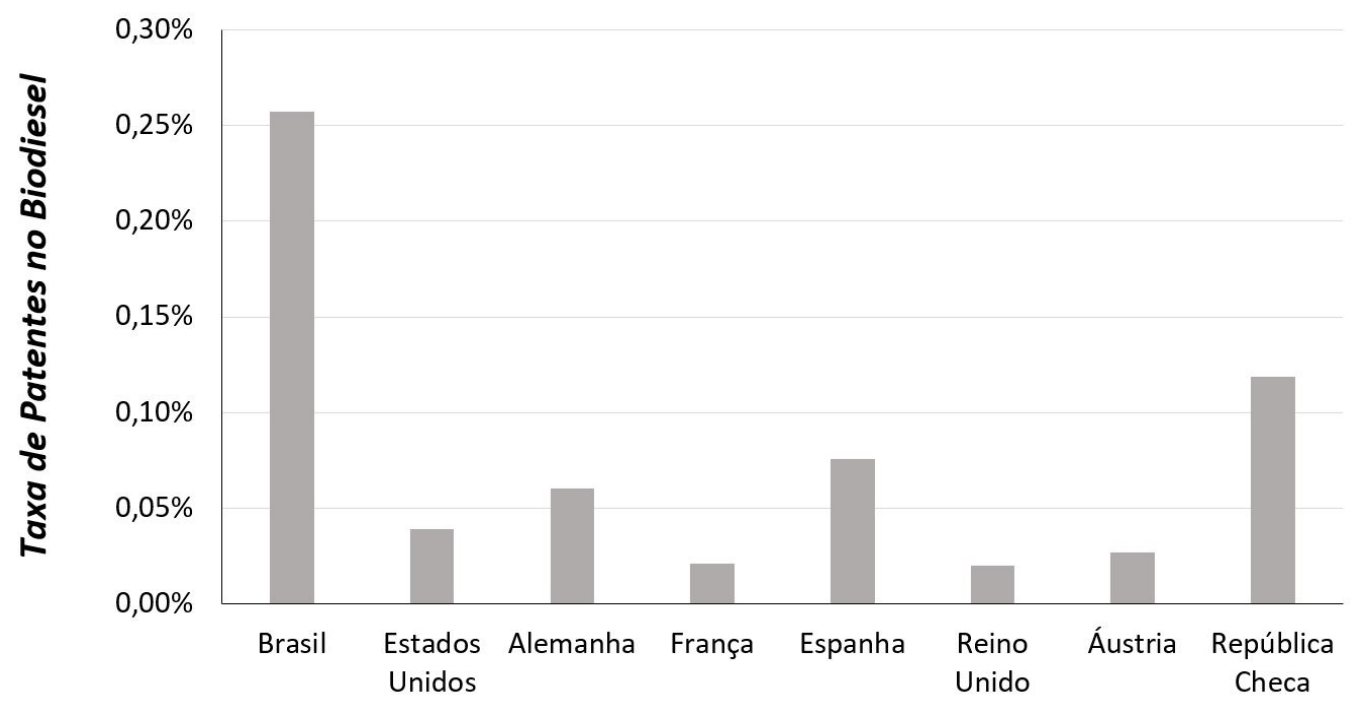

Figura 3 - Participação (\%) das patentes em biodiesel no total de patentes em todas as áreas do conhecimento depositadas por residente ${ }^{1}$ no período de 2000 - 2011². Fonte: Elaboração própria.

Notas: ${ }^{1}$ Fonte dos dados sobre as patentes em todas as áreas do conhecimento: WIPO statistics database: 2- Total Patent Grants (direct and PCT national phase entries): Resident non-resident count by filling office. Disponível em: http://ipstats.wipo.int/ipstatv2/index.htm?tab=patent. Versão atualizada em: março/2015. ${ }^{2}$ Essa taxa é calculada com base em dados sobre o total de patentes, não de famílias de patentes, pois a análise em termos relativos elimina aquele efeito apontado por Johnstone et al.

(2010), descrito na subseção "Base de Dados".

\subsection{Modelo Empírico}

Com o objetivo de averiguar se a tendência de alta no preço do petróleo, as políticas regulatória e fiscal e a proporção do gasto do governo em P\&D afetam a inovação no setor de biodiesel, analisa-se o resultado econométrico apresentado na Tabela 2, referente ao modelo especificado na Equação 9. Visto que a variável estoque contém um termo autorregressivo em sua formulação, gerando correlação entre uma variável explicativa e o termo de erro, para obtenção de estimativas consistentes, é estimado o modelo Poisson de Efeito Fixo por GMM de dois passos que usa termos defasados da variável como instrumentos na equação em quase-diferença proposta por Chamberlain (1992).

Antes de iniciar a análise dos coeficientes estimados é preciso verificar a validade dos instrumentos pela computação da estatística do teste J de Hansen (1982). Com $\chi^{2}(1)=2,0637$ não há evidência para rejeição da hipótese nula de que os instrumentos são válidos a 10\% de significância. O modelo é sobre identificado, pois 1 é a diferença entre o número de instrumentos e parâmetros estimados. Neste caso, por exemplo, $E_{i, t-2}$ e $E_{i, t-3}$ são instrumentos utilizados para a variável de estoque $E_{i \ddot{i}}$.

Tabela 2 - Coeficientes estimados para o modelo de Poisson de Efeito Fixo

\begin{tabular}{ccc} 
Variável & Poisson de Efeito Fixo (MMG) & Efeito Marginal \\
cresCons $_{i t}$ & $8,46 \mathrm{e}-07^{* * *}$ & $4,67 \mathrm{e}-06$ \\
& $1(2,12 \mathrm{e}-07)$ & \\
\hline
\end{tabular}

Fonte: Elaboração própria. Notas: 'Valores entre parênteses são os erros-padrão. ${ }^{* \star \star}$ Coeficiente significativo a $1 \%$. *Coeficiente significativo a 10\%. ${ }^{2}$ Estatística do teste J de Hansen de sobre identificação. 
Tabela 2 - Continuação...

\begin{tabular}{|c|c|c|}
\hline Variável & Poisson de Efeito Fixo (MMG) & Efeito Marginal \\
\hline Ppetro $_{i t}$ & $\begin{array}{l}0,0805 * \star * \\
(0,0246)\end{array}$ & 0,4446 \\
\hline$t x P \& D g o v_{i t}$ & $\begin{array}{l}0,3483^{* * *} \\
(0,1304)\end{array}$ & 1,9231 \\
\hline politica & $\begin{array}{c}0,9901^{*} \\
(0,5092)\end{array}$ & 5,4659 \\
\hline$E_{i, t-1}$ & $\begin{array}{l}0,0055^{* * *} \\
(0,0005)\end{array}$ & 0,0301 \\
\hline$t$ & $\begin{array}{l}-0,8175^{* * *} \\
(0,0513)\end{array}$ & $-4,5134$ \\
\hline $2 \chi^{2}(1)$ & 2,3322 & - \\
\hline Valor-p & 0,1267 & - \\
\hline
\end{tabular}

Fonte: Elaboração própria. Notas: ${ }^{V}$ Valores entre parênteses são os erros-padrão. ***Coeficiente significativo a $1 \%$. *Coeficiente significativo a $10 \%$. ${ }^{2}$ Estatística do teste J de Hansen de sobre identificação.

Pode-se verificar que todas as variáveis têm coeficientes estatisticamente diferentes de zero, representando, portanto, fatores que determinam a inovação no biodiesel. O coeficiente negativo da variável $t$ ratifica a existência de tendência decrescente na emissão de patentes com o passar do tempo, conforme já observada e explicada na Figura 2a. Todas as demais variáveis explicativas exercem influência positiva sobre a inovação como pressupõe a teoria. Mais diretamente, ratifica-se que a taxa de crescimento do consumo de biodiesel e o estoque de conhecimento atuam como fatores demand-pulle technology-push, respectivamente.

Quando a política pública (políticas regulatória e fiscal, simultaneamente) é introduzida no mercado de biodiesel, verifica-se aumento de aproximadamente 1\%, em média, na emissão de patentes ceteris paribus. Ambas políticas atuam como determinantes demand-pull, na medida em que asseguram, respectivamente, demanda ao produtor pelo estabelecimento de meta de consumo ou produção e reduzem custos de produção pela redução tributária e/ou concessão de subsídios. Já a política governamental de investimento em P\&D é um determinante do tipo technology-push, pois aumenta a capacidade tecnológica nacional, da qual o setor de biodiesel pode se beneficiar. Constata-se que o aumento de 1 unidade percentual da participação governamental no total bruto investido em P\&D é acompanhado, em média, pelo aumento de $0,35 \%$ no total de patentes emitidas, ceteris paribus.

Fornecendo evidência à teoria da inovação induzida, percebe-se que o aumento de um dólar no preço do barril de petróleo é acompanhado pelo aumento de aproximadamente 0,08\% no total de patentes em biodiesel. Ou seja, com a tendência de aumento relativo no preço do petróleo investe-se no biodiesel como uma tecnologia alternativa no sentido de tornar-se menos intensivo em petróleo, o que reduz custos de produção.

Para obtenção do efeito marginal de cada variável sobre o número de patentes, multiplica-se cada coeficiente $\beta_{k}$ estimado por 5,52, valor estimado da média condicional de patentes emitidas por país ao ano. Quando a análise é realizada em termos de efeito marginal, pode-se dizer que a introdução da política pública no mercado de biodiesel aumenta pouco mais de 5 unidades, em média, o total de patentes emitidas ceteris paribus. $\mathrm{O}$ aumento em uma unidade percentual da participação governamental no total bruto investido em P\&D é acompanhado pelo aumento de aproximadamente 1,92 patentes emitidas. Por fim, o aumento de um dólar no preço do barril de petróleo é acompanhado pelo aumento de 0,44 patentes em biodiesel. 
Portanto, parece haver evidências empíricas favoráveis à hipótese de que os fatores de mercado e a política pública atuam como determinantes da inovação no biodiesel no Brasil, Estados Unidos e principais países produtores da União Europeia.

Em relação à literatura empírica apresentada, pode-se observar que o resultado alcançado para o efeito do preço do petróleo converge para aqueles encontrados nos estudos de Karmarkar-Deshmukh \& Pray (2009), Jang \& Du (2013) e Lanzi et al. (2012) sobre o etanol e outras energias renováveis, em que o preço do combustível fóssil exerce influência positiva no que diz respeito à inovação nessas tecnologias alternativas. Em Jang \& Du (2013) e Kruse \& Wetzel (2015) é verificado, também, efeito positivo dos gastos em P\&D sobre a inovação em biocombustíveis. Diferentemente do constatado aqui, os dois primeiros estudos não encontraram qualquer efeito da política pública sobre a inovação. Já em Verdolini \& Galeotti (2011) e Brunnermeier \& Cohen (2003), observa-se que a existência de política pública também exerce efeito positivo na inovação em tecnologias relacionadas à energia e ao meio ambiente, respectivamente.

\section{Conclusões}

Para promover o crescimento sustentável das economias, demandas internacionais relacionadas à mitigação do processo de mudanças climáticas e problemas ambientais ligados ao aquecimento global somam-se às tradicionais preocupações das nações em garantir segurança energética frente à tendência crescente no preço do petróleo e episódios de restrição de sua oferta. Neste contexto, em que o setor de transportes está entre os líderes em emissões de GEE, o estímulo ao desenvolvimento e produção dos biocombustíveis por meio de programas e políticas governamentais tem se tornado estratégico para aumentar o emprego da energia renovável, diversificando a matriz energética. Enquanto o diesel é o principal combustível fóssil derivado do petróleo consumido neste setor, o biodiesel apresenta-se como uma alternativa efetiva para a sua substituição parcial e diminuição das emissões de GEE. Nesse sentido, teve-se como objetivo investigar como as políticas públicas e a tendência crescente no preço do combustível fóssil atuam no desenvolvimento da inovação no setor de biodiesel dos Estados Unidos, Brasil e principais países produtores da União Europeia.

Com o suporte da teoria da inovação induzida e por método econométrico apropriado para lidar com dados do tipo contagem e com a endogeneidade, foram encontradas evidências empíricas favoráveis à hipótese de que os fatores de mercado e as políticas públicas afetam positivamente a inovação no biodiesel, conforme o objetivo apresentado. Logo, o aumento no preço do petróleo induz inovação no biodiesel à proporção que se busca minimizar custos pelo desenvolvimento e emprego de tecnologias alternativas. A presença de metas quantitativas de produção ou consumo de biodiesel simultânea à existência de isenções tributárias e/ou concessão de subsídios também exerce efeito positivo sobre a inovação em biodiesel, haja vista que, enquanto a política regulatória assegura demanda em certo grau, a política fiscal diminui custos do biodiesel, tornando-o relativamente mais barato. A política governamental de investimento em P\&D também contribui para aumentar a inovação no biodiesel por aumentar a capacidade tecnológica nacional disponível a esse setor.

Deste modo, conclui-se que os objetivos nacionais de garantir segurança energética e mitigar o aquecimento global pela diversificação da matriz energética, com o crescimento da produção e consumo de energias renováveis, juntamente com a tendência de elevação no preço do petróleo têm constituído, efetivamente, importantes fatores para o desenvolvimento tecnológico do setor de biodiesel dos maiores países produtores. Portanto, em momentos de 
alta na oferta de combustíveis fósseis e queda relativa de seu preço, o investimento público em P\&D e a adoção de políticas podem ser fatores importantes para o contínuo desenvolvimento estratégico da inovação no biodiesel e manutenção do compromisso de aumentar a participação de energias renováveis na matriz energética.

Uma limitação que poderia ser apontada refere-se à inexistência de uma medida confiável que pondere as patentes e, consequentemente, o estoque de patentes por qualidade ou importância à geração de conhecimento. Sendo, assim, utilizada uma medida simples nesta pesquisa.

\section{Referências}

Ahmad, S. (1966). On the Theory of Induced Innovation. Economic Journal, 76(302), 344-357. http://dx.doi.org/10.2307/2229720

Associação dos Produtores de Biocombustíveis do Brasil - APROBIO. (2020). Ano começa com publicação do Edital do Leilão de Biodiesel (L78), primeiro para atender a mistura B13, e mobilização do setor para enfrentar novos desafios. Recuperado em 27 de fevereiro de 2020, de https://aprobio.com.br/noticia/pano-comeccedila-com-publicaccedilatildeo-do-edital-doleilatildeo-de-biodiesel-178-primeiro-para-atender-a-mistura-b13-e-mobilizaccedilatildeo-do-setor-para-enfrentar-novos-desafiosp

Brasil. Ministério do Desenvolvimento Agrário. (2013). Recuperado em 2 de novembro de 2013, de http://portal.mda.gov.br/portal/saf/programas/biodiesel/2286217

British Petroleum. (2013). BP statistical review of world energy june 2013. London: BP. Recuperado em 27 de fevereiro de 2020, de https://www.bp.com/en/global/corporate/energy-economics/ statistical-review-of-world-energy.html

Brunnermeier, S. B., \& Cohen, M. A. (2003). Determinants of environmental innovation in US manufacturing industries. Journal of Environmental Economics and Management, 45(2), 278-293. http://dx.doi.org/10.1016/S0095-0696(02)00058-X

Cameron, A. C., \& Trivedi, P. K. (2015). Count panel data. In B. H. Baltagi (Ed.), The Oxford handbook of panel data econometrics (Chap. 8, pp. 233-256). New York: Oxford University Press. Recuperado em 27 de fevereiro de 2020, de http://cameron.econ.ucdavis.edu/ research/Cameron_Trivedi_Panel_Count_Handbook_2015.pdf

Carvalho, C. H. R. (2011). Emissões relativas de poluentes do transporte motorizado de passageiros nos grandes centros urbanos brasileiros (Texto para Discussão, No. 1606). Brasília: IPEA. Recuperado em 27 de fevereiro de 2020, de https://www.ipea.gov.br/portal/ index.php?option=com_content $\&$ view $=$ article\&id $=9567$

Chamberlain, G. (1992). Comment: sequential moment restrictions in panel data. Journal of Business \& Economic Statistics, 10(1), 20-26. http://dx.doi.org/10.2307/1391799

Cohen, W. M., \& Levin, R. C. (1989). Empirical studies of innovation and market structure. In Schmalanse, R.; Willing, R. (Eds.). Handbook of industrial organization (Chap. 18, Vol. 2, pp. 1059-1107). Amsterdam: Elsevier B.V. https://doi.org/10.1016/S1573-448X(89)02006-6

Cohen, W. M., \& Levinthal, D. A. (1989). Innovation and learning: the two faces of R\&D. Economic Journal (London), 99(397), 569-596. http://dx.doi.org/10.2307/2233763

Costa, A. B. (2016). Teoria econômica e política de inovação. Revista de Economia Contemporânea, 20(2), 281-307. http://dx.doi.org/10.1590/198055272024 
Diop, D., Blanco, M., Flammini, A., Schlaifer, M., Kropiwnicka, M. A., \& Markhof, M. M. (2013). Assessing the impact of biofuels production on developing countries from the point of view of Policy Coherence for Development: final report. Brussels: AETS Consortium, European Comission. Recuperado em 27 de fevereiro de 2020, de https://www.researchgate.net/profile/ Maria-Blanco-33/publication/267037850_Assessing_the_impact_of_biofuels_production_ on_developing_countries_from_the_point_of_view_of_Policy_Coherence_for_Development/ links/5b1ec14e0f7e9b0e373dc969/Assessing-the-impact-of-biofuels-production-ondeveloping-countries-from-the-point-of-view-of-Policy-Coherence-for-Development.pdf

Dosi, G. (1982). Technological paradigms and technological trajectories: a suggested interpretation of the determinants and directions of technical change. Research Policy, 11(3), 147-162. http://dx.doi.org/10.1016/0048-7333(82)90016-6

Empresa de Pesquisa Energética - EPE. (2013a). Análise de conjuntura dos biocombustíveis/ano base 2012. Relatório final. Brasília: EPE. Recuperado em 27 de fevereiro de 2020, de https:// www.epe.gov.br/sites-pt/publicacoes-dados-abertos/publicacoes/PublicacoesArquivos/ publicacao-395/An\%C3\%A1 lise\%20de\%20Conjuntura\%20BIOCOMBUST\%C3\%8DVEIS\%20 -\%20Ano\%202012.pdf

Empresa de Pesquisa Energética - EPE. (2013b). Balanço energético nacional/ano base 2012. Relatório final. Brasília: EPE. Recuperado em 27 de fevereiro de 2020, de https://www.epe. gov.br/sites-pt/publicacoes-dados-abertos/publicacoes/PublicacoesArquivos/publicacao-129/ topico-101/Relat\%C3\%B3rio\%20Final\%202013.pdf

European Biodiesel Board - EBB. (2013). Statistcs: 2011 production by country. Recuperado em 2 de outubro de 2013, de http://www.ebb-eu.org/stats.php

European Patent Organisation - EPO. (2020). Recuperado em 27 de fevereiro de 2020, de https://www.epo.org/searching-for-patents/data/coverage/regular.html

European Union. (2012). EU Transport in figures. Statistical Pocketbook 2012. Luxembourg: EU. http://dx.doi.org/10.2832/52252

Food and Agriculture Organization of the United Nations - FAO. (2008). The state of food and agriculture. BIOFUELS: prospects, risks and opportunities. Rome: FAO. Recuperado em 27 de fevereiro de 2020, de http://www.fao.org/3/i0100e/i0100e.pdf

Freitas, L. C., \& Kaneko, S. (2012). Is there a causal relation between ethanol innovation and the market characteristics of fuels in Brazil? Ecological Economics, 74, 161-168. http://dx.doi. org/10.1016/j.ecolecon.2011.12.013

Greenpeace. (2016). [R]evolução energética: rumo a um Brasil com 100\% de Energias limpas e renováveis. Relatório Cenário Brasileiro 2016. São Paulo. Recuperado em 27 de fevereiro de 2020, de https://www.greenpeace.org/static/planet4-brasil-stateless/2018/07/Relatorio_ RevolucaoEnergetica2016_completo.pdf

Griliches, Z. (1990). Patent statistics as economic indicator: a survey. Journal of Economic Literature, 28(4), 1661-1707. Recuperado em 27 de fevereiro de 2020, de https://www. jstor.org/stable/2727442?seq=1

Hansen, L. P. (1982). Large sample properties of generalized method of moments estimators. Econometrica, 50(4), 1029-1054. http://dx.doi.org/10.2307/1912775

Hayami, Y., \& Ruttan, V. W. (1985). Agricultural development: an international perspective (rev. ed.). London: John Hopkins Press.

Hicks, J. (1932). The theory of wages. London: Macmillan. https://doi.org/10.2307/2224288 
High Level Panel of Experts on Food Security and Nutrition - HLPE. (2013). Biofuels and food security (Report, No. 5). Rome: HLPE. Recuperado em 27 de fevereiro de 2020, de http:// www.fao.org/3/i2952e/i2952e.pdf

Instituto Nacional de Propriedade Industrial - INPI. (2008a). Mapeamento tecnológico do biodiesel e tecnologias correlatas sob o enfoque dos pedidos de patentes: volume II - Brasil. Rio de Janeiro: INPI. Recuperado em 27 de fevereiro de 2020, de https://www.wipo.int/edocs/ plrdocs/en/biodiesel_vol2_brasil.pdf

Instituto Nacional de Propriedade Industrial - INPI. (2008b). Mapeamento tecnológico do biodiesel e tecnologias correlatas sob o enfoque dos pedidos de patentes: volume III - pedidos de patentes em biodiesel depositados nos Estados Unidos, China e União Europeia. Rio de Janeiro: INPI. Recuperado em 27 de fevereiro de 2020, de https://www.gov.br/inpi/pt-br/ acesso-a-informacao/dados-abertos/arquivos/documentos/estudos-setoriais/es-2008-mtvoliii-biodiesel-eua-ch-eu.pdf

Instituto Nacional de Propriedade Industrial - INPI. (2008c). Pedidos de patentes sobre 0 biodiesel: pedidos publicados no $1^{\circ}$ semestre de 2008 (Alerta Tecnológico). Rio de Janeiro: INPI. Recuperado em 27 de fevereiro de 2020, de https://www.gov.br/inpi/pt-br/assuntos/ informacao/alertas-tecnologicos

Instituto Nacional de Propriedade Industrial - INPI. (2009a). Pedidos de patentes sobre o biodiesel: pedidos publicados no $2^{\circ}$ semestre de 2008 (Alerta Tecnológico, No. 2). Rio de Janeiro: INPI. Recuperado em 27 de fevereiro de 2020, de https://www.gov.br/inpi/pt-br/ assuntos/informacao/alertas-tecnologicos

Instituto Nacional de Propriedade Industrial - INPI. (2009b). Pedidos de patentes com tecnologias relativas a biodiesel: pedidos publicados no $1^{\circ}$ semestre de 2009 (Alerta Tecnológico, No. 17). Rio de Janeiro: INPI. Recuperado em 27 de fevereiro de 2020, de https://www.gov.br/ inpi/pt-br/assuntos/informacao/alertas-tecnologicos

Instituto Nacional de Propriedade Industrial - INPI. (2010a). Pedidos de Patentes com Tecnologias Relativas a Biodiesel: Pedidos Publicados no $2^{\circ}$ Semestre de 2009 (Alerta Tecnológico, No. 26). Rio de Janeiro: INPI. Recuperado em 27 de fevereiro de 2020, de https://www.gov.br/ inpi/pt-br/assuntos/informacao/alertas-tecnologicos

Instituto Nacional de Propriedade Industrial - INPI. (2010b). Pedidos de patentes com tecnologias relativas a biodiesel: pedidos publicados no $1^{\circ}$ semestre de 2010 (Alerta Tecnológico, No. 36). Rio de Janeiro: INPI. Recuperado em 27 de fevereiro de 2020, de https://www.gov.br/ inpi/pt-br/assuntos/informacao/alertas-tecnologicos

Instituto Nacional de Propriedade Industrial - INPI. (2011a). Pedidos de patentes com tecnologias relativas a biodiesel: pedidos publicados no $2^{\circ}$ semestre de 2010 (Alerta Tecnológico, No. 47). Rio de Janeiro: INP. Recuperado em 27 de fevereiro de 2020, de https://www.gov.br/ inpi/pt-br/assuntos/informacao/alertas-tecnologicos

Instituto Nacional de Propriedade Industrial - INPI. (2011b). Pedidos de patentes com tecnologias relativas a biodiesel: pedidos publicados no $1^{\circ}$ semestre de 2011 (Alerta Tecnológico, No. 58). Rio de Janeiro: INPI. Recuperado em 27 de fevereiro de 2020, de https://www.gov.br/ inpi/pt-br/assuntos/informacao/alertas-tecnologicos

Instituto Nacional de Propriedade Industrial - INPI. (2012). Pedidos de patentes com tecnologias relativas a biodiesel: pedidos publicados no $2^{\circ}$ semestre de $2011 n^{\circ} 8$ (Alerta Tecnológico, No. 73). Rio de Janeiro: INPI. Recuperado em 27 de fevereiro de 2020, de https://www.gov. br/inpi/pt-br/assuntos/informacao/alertas-tecnologicos 
International Energy Agency - IEA. (2012). CO2 emissions from fuel combustion 2012. Paris: OECD Publishing. https://doi.org/10.1787/co2_fuel-2012-en

International Energy Agency - IEA. (2013). Key world energy statistics. Paris: OECD Publishing. International Energy Agency - IEA. (2015). IEA/IRENA global renewable energy policies and measures database. recuperado em 2 de setembro de 2015, de https://www.iea.org/ policies/about

International Monetary Fund. (2015). eLibrary data: time series. Recuperado em 2 de setembro de 2015, de https://data.imf.org/?sk=388dfa60-1d26-4ade-b505-a05a558d9a42

Jang, H., \& Du, X. (2013). Price- and policy-induced innovations: the case of U.S. biofuel. Journal of Agricultural and Resource Economics, 38(3), 299-311. http://dx.doi.org/10.22004/ag.econ.165929

Johnstone, N., Haščič, I., \& Popp, D. (2010). Renewable energy policies and technological innovation: evidence based on patent counts. Environmental and Resource Economics, 45, 133-155. http://dx.doi.org/10.1007/s10640-009-9309-1

Karmarkar-Deshmukh, R., \& Pray, C. E. (2009). Private Sector innovation in biofuels in the united states: induced by prices or policies? AgBioForum, 12(1), 141-148. Recuperado em 27 de fevereiro de 2020, de https://agbioforum.org/private-sector-innovation-in-biofuels-in-theunited-states-induced-by-prices-or-policies/

Kruse, J., \& Wetzel, H. (2015). Energy prices, technological knowledge, and innovation in green energy technologies: a dynamic panel analysis of european patent data. CESifo Economic Studies, 62(3), 397-425. https://doi.org/10.1093/cesifo/ifv021

Lanzi, E., Haščič, l., \& Johnstone, N. (2012). The determinants of invention in electricity generation technologies: a patent data analysis (OECD Environment Working Papers, No. 45). Paris. https://doi.org/10.1787/5k92v111shjc-en

Mowery, D., \& Rosenberg, N. (1979). The influence of market demand upon innovation: a critical review of some recent empirical studies. Research Policy, 8(2), 102-153. http://dx.doi. org/10.1016/0048-7333(79)90019-2

Popp, D. (2002). Induced innovation and energy prices. The American Economic Review, 92(1), 160-180. http://dx.doi.org/10.1257/000282802760015658

Rosenberg, N. (1974). Science, invention and economic growth. Economic Journal, 84(33), 90108. http://dx.doi.org/10.2307/2230485

Schmookler, J. (1966). Invention and economic growth. Cambridge: Harvard University Press.

Schumpeter, J. A. (1939). Business cycles: a theoretical, historical and statistical analysis of the capitalist process. New York: McGraw-Hill.

U.S. Energy Information Administration - EIA. (2015). Independent Statistics \& Analysis. International. Data. Recuperado em 2 de novembro de 2015, de https://www.eia.gov/international/data/world

United Nations Educational, Scientific and Cultural Organization - UNESCO. UNESCO Institute for Statistics - UIS. (2015). Stat: science, technology and innovation. Recuperado em 2 de novembro de 2015, de http://data.uis.unesco.org/

United States Department of Labor Bureau of Labor Statistics. (2015). Data tools: top picks: all urban consumers - CPI: U.S. All items, 1982-84=100 - CUUROOOOSAO. Recuperado em 2 de novembro de 2015, de http://data.bls.gov/cgi-bin/surveymost?cu

Verdolini, E., \& Galeotti, M. (2011). At home and abroad: an empirical analysis of innovation and diffusion in energy technologies. Journal of Environmental Economics and Management, 61(2), 119-134. http://dx.doi.org/10.1016/j.jeem.2010.08.004 
World Intellectual Property Organization - WIPO. (2013). Terms and abbreviations: handbook on industrial property information and documentation. Geneva: WIPO. Recuperado em 27 de fevereiro de 2020, de https://www.wipo.int/export/sites/www/standards/en/pdf/08-01-01.pdf

Recebido: Fevereiro 27, 2020;

Aceito: Abril 15, 2021

JEL Classification: Q41, Q42, Q48, Q55, Q58. 


\section{APÊNDICE}

Quadro - Registros publicados no estudo do INPI que não foram encontrados no site Espacenet (EPO) durante a busca por patente

\begin{tabular}{|c|c|c|c|c|}
\hline DE10293630D & DE50201102D & DE59811972D & DK635558T & DE59812723D \\
\hline DE10393708D & DE50307153D & DE60218677D & DK775185T & DE50112468D \\
\hline DE3573131D & DE58904306D & DE69110036D & DE10190350D & DE50203532D \\
\hline DE3660766D & DE59204655D & DE50007569D & DE10390808D & DE59600596D \\
\hline DE3661192D & DE59208211D & DE50012237D & DE50012598D & DK771599T \\
\hline DE50003549D & DE59300838D & DE59106692D & DE50105819D & DK900822T \\
\hline DE50006589D & DE59401356D & DE59807089D & DE50200261D & DE59804844D \\
\hline DE50103259D & DE59409130D & DE59810929D & DE69405895D & DK523767T \\
\hline DE50103724D & DE59700863D & DE69815447D & DE69804541D & DK562504T \\
\hline & & & & DK855436T \\
\cline { 4 - 5 } DE50112634D & DE59804365D & DE69831261D & DK953105T & DK931051T \\
\cline { 4 - 5 } & & & & SK200000772 \\
\hline
\end{tabular}

Fonte: Instituto Nacional da Propriedade Industrial (2008b). 